\title{
FACT-MNG: tumor site specific web-based outcome instrument for meningioma patients
}

\author{
D. Zlotnick $\cdot$ S. N. Kalkanis $\cdot$ A. Quinones-Hinojosa $\cdot$ K. Chung $\cdot$ \\ M. E. Linskey $\cdot$ R. L. Jensen - F. DeMonte - F. G. Barker • C. A. Racine • \\ M. S. Berger $\cdot$ P. M. Black $\cdot$ M. Cusimano $\cdot$ L. N. Sekhar $\cdot$ A. Parsa • \\ M. Aghi $\cdot$ Michael W. McDermott
}

Received: 20 July 2010/ Accepted: 30 August 2010/Published online: 18 September 2010

(C) The Author(s) 2010. This article is published with open access at Springerlink.com

\begin{abstract}
To formulate Functional Assessment of Cancer Therapy-Meningioma (FACT-MNG), a web-based tumor site-specific outcome instrument for assessing intracranial meningioma patients following surgical resection or stereotactic radiosurgery. We surveyed the relevant literature available on intracranial meningioma surgery and subsequent outcomes (38 papers), making note of which, if any, QOL/outcome instruments were utilized. None of the surgveyed papers included QOL assessment specific to tumor site. We subsequently developed questions that were relevant to the signs and symptoms that characterize each
\end{abstract}

\section{Zlotnick}

University of Calfiornia, Irvine, 3034 Hewitt Hall, Bldg. 843, Irvine, CA 92697-4120, USA

\section{S. N. Kalkanis}

Henry Ford Department of Neurosurgery, Henry Ford Hospital, 2799 West Grand Boulevard, Detroit, MI 48201, USA

\section{A. Quinones-Hinojosa \\ Department of Neurosurgery, Johns Hopkins University, School of Medicine, Cancer Research, Building II 1550 Orleans Street, Room 247, Baltimore, MD 21231-1044, USA}

K. Chung - C. A. Racine - M. S. Berger - A. Parsa $\cdot$ M. Aghi Department of Neurological Surgery, University of California, San Francisco, 505 Parnassus Ave., M-779, San Francisco, CA 94143-0112, USA

M. E. Linskey

Department of Neurosurgery, University of California-Irvine Medical Center, Orange, CA, USA

\section{R. L. Jensen}

Department of Neurosurgery, Huntsman Cancer Institute, University of Utah Health Sciences Center, 5th Floor, Clinical Neurosciences Center, 175 North Medical Drive, Salt Lake City, UT 84132, USA of 11 intracranial meningioma sites, and incorporated them into a modified combination of the Functional Assessment of Cancer Therapy-Brain (FACT-BR) and SF36 outcome instruments, thereby creating a new tumor site-specific outcome instrument, FACT-MNG. With outcomes analysis of surgical and radiosurgical treatments becoming more important, measures of the adequacy and success of treatment are needed. FACT-MNG represents a first effort to formalize such an instrument for meningioma patients. Questions specific to tumor site will allow surgeons to better assess specific quality of life issues not addressed in the past by more general questionnaires.

\author{
F. DeMonte \\ Department of Neurosurgery, The University of Texas MD \\ Anderson Cancer Center, Houston, TX, USA \\ F. G. Barker \\ Department of Neurosurgery, Massachusetts General Hospital, \\ Boston, MA 02114, USA \\ P. M. Black \\ Department of Neurosurgery, Brigham \& Women's Hospital, \\ 75 Francis Street, Boston, MA 02115, USA \\ M. Cusimano \\ Department of Neurosurgery, University of Toronto, \\ 2 Queen St., E. Suite 1005, Toronto, ON M5C 3G7, Canada \\ L. N. Sekhar \\ Harborview Medical Center UW Medicine, Department of \\ Neurosurgery, Box 359924, 325 Ninth Avenue, Seattle, \\ WA 98104-2499, USA \\ M. W. McDermott ( $₫)$ \\ Department of Neurological Surgery, University of California, \\ San Francisco, 505 Parnassus Ave., M-780, San Francisco, \\ CA 94143-0112, USA \\ e-mail: mcdermottm@neurosurg.ucsf.edu
}


Keywords Meningioma - Intracranial surgery · Radiotherapy · Quality of life

\section{Introduction}

Outcomes and Quality of Life (QOL) assessment instruments are important for assessing the results of surgical and radiosurgical treatment, as well as comparing results across studies [16]. Many of these instruments assess QOL but not in a manner that addresses the CNS symptoms/signs of specific tumor sites. This becomes increasingly relevant when dealing with tumors that tend to arise in specific intracranial locations which can lead to distinct symptom complexes with unique effects on QOL that can be overlooked by less specific QOL instruments. Recognizing these location-specific symptom complexes allow us the opportunity to personalize the QOL assessment towards distinct patient groups.

Meningiomas comprise one such class of location-specific intracranial tumors [31]. Accounting for some $20 \%$ of intracranial tumors, they are generally histologically benign and slow growing, but may become locally invasive. Due to the risk of tumor growth and development of focal neurological deficits from mass effect, standard treatment usually consists of surgical resection or stereotactic radiosurgery.

QOL assessment provides information regarding efficacy of surgical/radiosurgical treatment and may serve as an important decision-making tool for patients and physicians who are weighing the risks and benefits of brain surgery, especially if their meningioma is of the benign variety. While there are a variety of outcome assessment tools currently available, they vary widely in terms of scope (post-surgery QOL, post-cancer therapy QOL, postbrain surgery QOL, etc.), and none are currently locationspecific. Currently, the instrument most accurately targeted at assessing QOL following brain tumor resection is the validated Functional Assessment of Cancer Therapy-Brain (FACT-BR) [22, 23, 40].
The location-specific nature of clinical symptoms and signs of intracranial meningiomas provides an opportunity for an even more targeted QOL assessment; one that takes into account site-specific symptoms [42]. This would allow for a more detailed examination of an individual patient's QOL based on tumor site and pre/post-surgery signs and symptoms. With these goals in mind, FACTMNG was created. An important part of developing such an instrument was making it available freely in a web based platform so that patients could access the questionnaire on regular set intervals without the need for direct physician contact or instruction. The VisionTree Optimal Care ${ }^{\mathrm{TM}}$ (VTOC) secure web-based portal allows for patients to enter the site through self-registration and complete the FACT-MNG electronically. Upon registration, the patient automatically receives an email with their secure login information providing ongoing access to the survey. VTOC includes full reporting/tracking capabilities to query the data which can be exported to Excel for additional analysis.

\section{Methods}

Initial data was gathered by way of reviewing relevant literature (via PubMed) which discussed and examined intracranial meningioma surgical therapy as well as subsequent outcomes. With 38 papers $[1-15,17-22,24-30$, $32-41]$ in hand meeting our search criteria, we reviewed the assessment instruments utilized in each. While all of the papers included outcomes, when it came to QOL assessment, 2 of the 38 used SF36 [3, 19, 39] others used FACT-BR [5, 22, 40], and 8 used a more basic patient functionality-oriented Karnofsky Performance Status (KPS) comparison [10, 13, 28, 32, 34, 36, 37], and less than half (15 of 38 papers) utilized any QOL instrument at all (FACT-BR, SF36, KPS Scale, or some other instrument). None of the papers utilized site-specific questions.

Table 1 SF-36 Questions incorporated into FACT-MNG

\begin{tabular}{|c|c|c|c|c|c|}
\hline & Not at all & A little bit & Somewhat & Quite a bit & Very much \\
\hline $\begin{array}{l}\text { I am limited in performing vigorous activities, such as running, } \\
\text { lifting heavy objects, participating in strenuous sports }\end{array}$ & 0 & 1 & 2 & 3 & 4 \\
\hline $\begin{array}{l}\text { I am limited in performing moderate activities, such as moving a table, } \\
\text { pushing a vacuum cleaner, bowling, or playing golf }\end{array}$ & 0 & 1 & 2 & 3 & 4 \\
\hline I have difficulty climbing several flights of stairs & 0 & 1 & 2 & 3 & 4 \\
\hline I have difficulty walking several blocks & 0 & 1 & 2 & 3 & 4 \\
\hline I have difficulty bathing or dressing myself & 0 & 1 & 2 & 3 & 4 \\
\hline
\end{tabular}


Table 2 Site-specific questions incorporated into FACT-MNG

\begin{tabular}{llllll}
\hline & $\begin{array}{l}\text { Not } \\
\text { at all }\end{array}$ & $\begin{array}{l}\text { A little } \\
\text { bit }\end{array}$ & Somewhat & $\begin{array}{l}\text { Quite } \\
\text { a bit }\end{array}$ & $\begin{array}{l}\text { Very } \\
\text { much }\end{array}$ \\
\hline
\end{tabular}

Olfactory Groove Meningioma

My sense of smell is altered

My sense of taste is altered

My vision is altered

My short term memory is worse

Tuberculum sellae meningioma

My vision is altered

Compared to before my surgery, my vision is improved

My short term memory is worse

Optic nerve sheath meningioma

My vision is altered

Compared with prior to treatment, my vision is improved

Sphenoid wing meningioma

My vision is altered

Compared with prior to treatment, my vision is improved

I have numbness on my forehead

I have numbness on my cheek

I have double vision

My short term memory is worse

Cavernous sinus meningioma

My vision is altered

I have double vision

I have numbness on my forehead

I have numbness on my cheek

I have numbness on my chin

Parasagittal/falx meningioma

My short term memory is worse

My leg is weak

My leg is numb

My arm is weak

My arm is numb

I have a blind spot in my vision

Tentorial meningioma

My vision is altered

I have double vision

I have numbness on my face

My short term memory is worse

I have a blind spot in my vision

Petroclival meningioma

My vision is altered

I have double vision

I have numbness on my face

My short term memory is worse

My coordination is affected

My arm is uncoordinated

My leg is uncoordinated
2

2

2

2

2

2

2

3

4

4

4

4

4

4

4

4

4

0

2

2

3

3

4

4

4

4

4

4

4

4

4

4

4

4

4

4

4

4

4

0

4

4

4

4

4

4

4

4

4

4

4

4 
Table 2 continued

\begin{tabular}{|c|c|c|c|c|c|}
\hline & $\begin{array}{l}\text { Not } \\
\text { at all }\end{array}$ & $\begin{array}{l}\text { A little } \\
\text { bit }\end{array}$ & Somewhat & $\begin{array}{l}\text { Quite } \\
\text { a bit }\end{array}$ & $\begin{array}{l}\text { Very } \\
\text { much }\end{array}$ \\
\hline My hearing is worse than prior to treatment & 0 & 1 & 2 & 3 & 4 \\
\hline My balance is worse than prior to treatment & 0 & 1 & 2 & 3 & 4 \\
\hline \multicolumn{6}{|l|}{ Cerebellopontine angle (CPA) meningioma } \\
\hline I have numbness on my face & 0 & 1 & 2 & 3 & 4 \\
\hline I have pain in my face & 0 & 1 & 2 & 3 & 4 \\
\hline My hearing is worse than prior to treatment & 0 & 1 & 2 & 3 & 4 \\
\hline I have ringing in my ear on the side of surgery & 0 & 1 & 2 & 3 & 4 \\
\hline I have weakness of my face & 0 & 1 & 2 & 3 & 4 \\
\hline I have problems with dizziness & 0 & 1 & 2 & 3 & 4 \\
\hline My balance is worse than prior to treatment & 0 & 1 & 2 & 3 & 4 \\
\hline My coordination is affected & 0 & 1 & 2 & 3 & 4 \\
\hline My arm is uncoordinated & 0 & 1 & 2 & 3 & 4 \\
\hline My leg is uncoordinated & 0 & 1 & 2 & 3 & 4 \\
\hline \multicolumn{6}{|l|}{ Cerebellar convexity meningioma } \\
\hline My coordination is affected & 0 & 1 & 2 & 3 & 4 \\
\hline My arm is uncoordinated & 0 & 1 & 2 & 3 & 4 \\
\hline My leg is uncoordinated & 0 & 1 & 2 & 3 & 4 \\
\hline My balance is worse than prior to treatment & 0 & 1 & 2 & 3 & 4 \\
\hline My arm is weak & 0 & 1 & 2 & 3 & 4 \\
\hline My leg is weak & 0 & 1 & 2 & 3 & 4 \\
\hline My arm is numb & 0 & 1 & 2 & 3 & 4 \\
\hline My leg is numb & 0 & 1 & 2 & 3 & 4 \\
\hline \multicolumn{6}{|l|}{ Foramen magnum meningioma } \\
\hline I have neck pain & 0 & 1 & 2 & 3 & 4 \\
\hline My speech is slurred & 0 & 1 & 2 & 3 & 4 \\
\hline I have trouble swallowing & 0 & 1 & 2 & 3 & 4 \\
\hline My voice is hoarse & 0 & 1 & 2 & 3 & 4 \\
\hline My balance is worse than prior to treatment & 0 & 1 & 2 & 3 & 4 \\
\hline My walking is worse than prior to treatment & 0 & 1 & 2 & 3 & 4 \\
\hline I have shoulder pain & 0 & 1 & 2 & 3 & 4 \\
\hline
\end{tabular}

\section{Results and discussion}

To address the issue of site specificity, we created FACTMNG (Functional Assessment of Cancer Therapy-Meningioma), an amalgamation of FACT-BR, SF36, and newly formulated questions addressing tumor site-specific signs and symptoms. Specifically, we started with FACT-BR as our base and added questions from SF36 that were more detailed in ascertaining the patient's physical capabilities (e.g., ability to perform light, mild, or strenuous activity without difficulty) (Table 1). Our most significant modification was the creation and inclusion of questions that were relevant to the signs and symptoms that characterize one of 11 tumor sites: olfactory groove, tuberculum sella, optic nerve sheath, sphenoid wing, cavernous sinus, parasagittal, tentorium cerebelli, petroclival region, cerebellopontine angle, cerebellar convexity, and foramen magnum (Table 2, 3).
Following its creation, FACT-MNG was converted into a web-based format (currently available for patients/physicians to download for free at https://www.optimal care.com. In addition to the benefits of offering FACTMNG digitally (streamlined data collection, storage, and analysis), the dynamic delivery offered by a web-based application allows patients to only answer questions pertinent to their tumor's site. At UCSF we plan to introduce patients to the web site and questionnaire with a small business card containing the web site URL and suggested time interval for assessment post-operatively at 3, 6, 12, 18, 24, 36, 48, 60, and 72 months. Any additional intervention will re-start the assessment clock for the initial intervention and begin a new follow-up session. The VTOC system can be configured to release the FACT-MNG into the patient's portal at the specific time points noted above. An email alert is automatically sent to remind the patient to login and complete the survey at each time interval. The process is 
Table 3 FACT-MNG

$\begin{array}{lllll}\begin{array}{l}\text { Not } \\ \text { at all }\end{array} & \begin{array}{l}\text { A little } \\ \text { bit }\end{array} & \text { Somewhat } & \begin{array}{l}\text { Quite } \\ \text { a bit }\end{array} & \begin{array}{l}\text { Very } \\ \text { much }\end{array}\end{array}$

Physical well-being

I have a lack of energy

I have nausea

Because of my physical condition, I have trouble meeting the needs of my family

I have pain

I am bothered by side effects of treatment

I feel ill

I am forced to spend time in bed

I am limited in performing vigorous activities, such as running, lifting heavy objects, participaing in strenuous sports

I am limited in performing moderate activities, such as moving a table, pushing a vacuum cleaner, bowling, or playing golf

I have difficulty climbing several flights of stairs

I have difficulty walking several blocks

I have difficulty bathing or dressing myself

Social/family well-being

I feel close to my friends

I get emotional support from my family

I get support from my friends

My family has accepted my illness

I am satisfied with family communication about my illness

I feel close to my partner (or the person who is my main support)

Regardless of your current level of sexual activity, please answer the following question.

If you prefer not to answer it, please check this box $\prod$ and go to the next section

I am satisfied with my sex life

Emotional well-being

I feel sad

I am satisfied with how I am coping with my illness

I am losing hope in the fight against my illness

I feel nervous

I worry about dying

I worry that my condition will get worse

Functional well-being

I am able to work (include work at home)

My work (include work at home) is fulfilling

I am able to enjoy life

I have accepted my illness

I am sleeping well

I am enjoying things I usually do for fun

I am content with the quality of my life right now

Additional concerns

I am able to concentrate

I have had headaches

I have had seizure convulsions

I can remember new things

I get frustrated that I cannot do the things I used to

I am afraid of having a seizure (convulsion)

I have trouble with my eyesight

$\begin{array}{lllll}0 & 1 & 2 & 3 & 4 \\ 0 & 1 & 2 & 3 & 4 \\ 0 & 1 & 2 & 3 & 4 \\ 0 & 1 & 2 & 3 & 4 \\ 0 & 1 & 2 & 3 & 4 \\ 0 & 1 & 2 & 3 & 4 \\ 0 & 1 & 2 & 3 & 4 \\ 0 & 1 & 2 & 3 & 4 \\ 0 & 1 & 2 & 3 & 4 \\ 0 & 1 & 2 & 3 & 4 \\ 0 & 1 & 2 & 3 & 4 \\ 0 & 1 & 2 & 3 & 4 \\ & & & & \\ 0 & 1 & 2 & 3 & 4 \\ 0 & 1 & 2 & 3 & 4 \\ 0 & 1 & 2 & 3 & 4 \\ 0 & 1 & 2 & 3 & 4 \\ 0 & 1 & 2 & 3 & 4 \\ 0 & 1 & 2 & 3 & 4\end{array}$

$\begin{array}{lllll}0 & 1 & 2 & 3 & 4 \\ 0 & 1 & 2 & 3 & 4 \\ 0 & 1 & 2 & 3 & 4 \\ 0 & 1 & 2 & 3 & 4 \\ 0 & 1 & 2 & 3 & 4 \\ 0 & 1 & 2 & 3 & 4 \\ 0 & 1 & 2 & 3 & 4\end{array}$


Table 3 continued

\begin{tabular}{|c|c|c|c|c|c|}
\hline & $\begin{array}{l}\text { Not } \\
\text { at all }\end{array}$ & $\begin{array}{l}\text { A little } \\
\text { bit }\end{array}$ & Somewhat & $\begin{array}{l}\text { Quite } \\
\text { a bit }\end{array}$ & $\begin{array}{l}\text { Very } \\
\text { much }\end{array}$ \\
\hline I feel independent & 0 & 1 & 2 & 3 & 4 \\
\hline I have trouble hearing & 0 & 1 & 2 & 3 & 4 \\
\hline I am able to find the right word(s) to say what I mean & 0 & 1 & 2 & 3 & 4 \\
\hline I have difficulty expressing my thoughts & 0 & 1 & 2 & 3 & 4 \\
\hline I am bothered by the change in my personality & 0 & 1 & 2 & 3 & 4 \\
\hline I am able to make decisions and take responsibility & 0 & 1 & 2 & 3 & 4 \\
\hline I am bothered by the drop in my contribution to the family & 0 & 1 & 2 & 3 & 4 \\
\hline I am able to put my hands together & 0 & 1 & 2 & 3 & 4 \\
\hline I need help caring for myself (bathing, dressing, eating, etc.) & 0 & 1 & 2 & 3 & 4 \\
\hline I am able to my thoughts into action & 0 & 1 & 2 & 3 & 4 \\
\hline I am able to read like I'm used to & 0 & 1 & 2 & 3 & 4 \\
\hline I am able to write like I'm used to & 0 & 1 & 2 & 3 & 4 \\
\hline I am able to drive a vehicle (my car, truck, etc.) & 0 & 1 & 2 & 3 & 4 \\
\hline \multicolumn{6}{|l|}{ Tumor site-specific questions } \\
\hline \multicolumn{6}{|l|}{ Olfactory Groove Meningioma } \\
\hline My sense of smell is altered & 0 & 1 & 2 & 3 & 4 \\
\hline My sense of taste is altered & 0 & 1 & 2 & 3 & 4 \\
\hline My vision is altered & 0 & 1 & 2 & 3 & 4 \\
\hline My short term memory is worse & 0 & 1 & 2 & 3 & 4 \\
\hline \multicolumn{6}{|l|}{ Tuberculum Sellae Meningioma } \\
\hline My vision is altered & 0 & 1 & 2 & 3 & 4 \\
\hline Compared to before my surgery, my vision is improved & 0 & 1 & 2 & 3 & 4 \\
\hline My short term memory is worse & 0 & 1 & 2 & 3 & 4 \\
\hline \multicolumn{6}{|l|}{ Optic Nerve Sheath Meningioma } \\
\hline My vision is altered & 0 & 1 & 2 & 3 & 4 \\
\hline Compared with prior to treatment, my vision is improved & 0 & 1 & 2 & 3 & 4 \\
\hline \multicolumn{6}{|l|}{ Sphenoid Wing Meningioma } \\
\hline My vision is altered & 0 & 1 & 2 & 3 & 4 \\
\hline Compared with prior to treatment, my vision is improved & 0 & 1 & 2 & 3 & 4 \\
\hline I have numbness on my forehead & 0 & 1 & 2 & 3 & 4 \\
\hline \multicolumn{6}{|l|}{ I have numbness on my cheek } \\
\hline I have double vision & 0 & 1 & 2 & 3 & 4 \\
\hline My short term memory is worse & 0 & 1 & 2 & 3 & 4 \\
\hline \multicolumn{6}{|l|}{ Cavernous Sinus Meningioma } \\
\hline My vision is altered & 0 & 1 & 2 & 3 & 4 \\
\hline I have double vision & 0 & 1 & 2 & 3 & 4 \\
\hline I have numbness on my forehead & 0 & 1 & 2 & 3 & 4 \\
\hline I have numbness on my cheek & 0 & 1 & 2 & 3 & 4 \\
\hline I have numbness on my chin & 0 & 1 & 2 & 3 & 4 \\
\hline \multicolumn{6}{|l|}{ Parasagittal/Falx Meningioma } \\
\hline My short term memory is worse & 0 & 1 & 2 & 3 & 4 \\
\hline My leg is weak & 0 & 1 & 2 & 3 & 4 \\
\hline My leg is numb & 0 & 1 & 2 & 3 & 4 \\
\hline My arm is weak & 0 & 1 & 2 & 3 & 4 \\
\hline My arm is numb & 0 & 1 & 2 & 3 & 4 \\
\hline I have a blind spot in my vision & 0 & 1 & 2 & 3 & 4 \\
\hline \multicolumn{6}{|l|}{ Tentorial Meningioma } \\
\hline My vision is altered & 0 & 1 & 2 & 3 & 4 \\
\hline
\end{tabular}


Table 3 continued

\begin{tabular}{|c|c|c|c|c|c|}
\hline & $\begin{array}{l}\text { Not } \\
\text { at all }\end{array}$ & $\begin{array}{l}\text { A little } \\
\text { bit }\end{array}$ & Somewhat & $\begin{array}{l}\text { Quite } \\
\text { a bit }\end{array}$ & $\begin{array}{l}\text { Very } \\
\text { much }\end{array}$ \\
\hline I have double vision & 0 & 1 & 2 & 3 & 4 \\
\hline I have numbness on my face & 0 & 1 & 2 & 3 & 4 \\
\hline My short term memory is worse & 0 & 1 & 2 & 3 & 4 \\
\hline I have a blind spot in my vision & 0 & 1 & 2 & 3 & 4 \\
\hline \multicolumn{6}{|l|}{ Petroclival Meningioma } \\
\hline My vision is altered & 0 & 1 & 2 & 3 & 4 \\
\hline I have double vision & 0 & 1 & 2 & 3 & 4 \\
\hline I have numbness on my face & 0 & 1 & 2 & 3 & 4 \\
\hline My short term memory is worse & 0 & 1 & 2 & 3 & 4 \\
\hline My coordination is affected & 0 & 1 & 2 & 3 & 4 \\
\hline My arm is uncoordinated & 0 & 1 & 2 & 3 & 4 \\
\hline My leg is uncoordinated & 0 & 1 & 2 & 3 & 4 \\
\hline My hearing is worse than prior to treatment & 0 & 1 & 2 & 3 & 4 \\
\hline My balance is worse than prior to treatment & 0 & 1 & 2 & 3 & 4 \\
\hline \multicolumn{6}{|l|}{ Cerebellopontine Angle (CPA) Meningioma } \\
\hline I have numbness on my face & 0 & 1 & 2 & 3 & 4 \\
\hline I have pain in my face & 0 & 1 & 2 & 3 & 4 \\
\hline My hearing is worse than prior to treatment & 0 & 1 & 2 & 3 & 4 \\
\hline I have ringing in my ear on the side of surgery & 0 & 1 & 2 & 3 & 4 \\
\hline I have weakness of my face & 0 & 1 & 2 & 3 & 4 \\
\hline I have problems with dizziness & 0 & 1 & 2 & 3 & 4 \\
\hline My balance is worse than prior to treatment & 0 & 1 & 2 & 3 & 4 \\
\hline My coordination is affected & 0 & 1 & 2 & 3 & 4 \\
\hline My arm is uncoordinated & 0 & 1 & 2 & 3 & 4 \\
\hline My leg is uncoordinated & 0 & 1 & 2 & 3 & 4 \\
\hline \multicolumn{6}{|l|}{ Cerebellar Convexity Meningioma } \\
\hline My coordination is affected & 0 & 1 & 2 & 3 & 4 \\
\hline My arm is uncoordinated & 0 & 1 & 2 & 3 & 4 \\
\hline My leg is uncoordinated & 0 & 1 & 2 & 3 & 4 \\
\hline My balance is worse than prior to treatment & 0 & 1 & 2 & 3 & 4 \\
\hline My arm is weak & 0 & 1 & 2 & 3 & 4 \\
\hline My leg is weak & 0 & 1 & 2 & 3 & 4 \\
\hline My arm is numb & 0 & 1 & 2 & 3 & 4 \\
\hline My leg is numb & 0 & 1 & 2 & 3 & 4 \\
\hline \multicolumn{6}{|l|}{ Foramen Magnum Meningioma } \\
\hline I have neck pain & 0 & 1 & 2 & 3 & 4 \\
\hline My speech is slurred & 0 & 1 & 2 & 3 & 4 \\
\hline I have trouble swallowing & 0 & 1 & 2 & 3 & 4 \\
\hline My voice is hoarse & 0 & 1 & 2 & 3 & 4 \\
\hline My balance is worse than prior to treatment & 0 & 1 & 2 & 3 & 4 \\
\hline My walking is worse than prior to treatment & 0 & 1 & 2 & 3 & 4 \\
\hline I have shoulder pain & 0 & 1 & 2 & 3 & 4 \\
\hline
\end{tabular}


fully automated within VTOC using templates and calendar reminders to ensure accuracy and compliance. A subset of patients may not be proficient with or have access to computers, either due to educational differences, socioeconomic status, or as a result of their disease process and/ or treatment. For these selected patients, notifications by mail can be utilized.

\section{Conclusion}

With QOL assessment becoming increasingly important as an information, education and -outcomes assessment tool for both physicians and patients, relying on an outcome instrument too general in scope may leave more detailed, but nonetheless pertinent, issues unexplored and unmeasured. While FACT-BR has been validated as an assessment tool pertaining to brain tumors in general, those tumors which associated with characteristic site-specific signs and symptoms readily lend themselves towards QOL assessment with an even further refined scope. Intracranial meningiomas offer one such opportunity and, on account of their comprising almost one-fifth of all intracranial tumors, warrant the development of an outcome instrument with a narrower scope.

This instrument is not yet clinically validated. Further examination of FACT-MNG should revolve around qualifying its validity as compared to the outcome assessment provided by other QOL instruments (most notably FACTBR) following meningioma surgical therapy. The authors of this paper plan to investigate the use of this instrument in a prospective fashion on their patient population and report on the results at a future date.

Acknowledgments The authors thank Meningioma Mommas for their financial support with this project and Vision Tree Software for their role in developing FACT-MNG into a web-based application.

Open Access This article is distributed under the terms of the Creative Commons Attribution Noncommercial License which permits any noncommercial use, distribution, and reproduction in any medium, provided the original author(s) and source are credited.

\section{References}

1. Abdel-Aziz KM, Froelich SC, Dagnew E et al (2004) Large sphenoid wing meningiomas involving the cavernous sinus: conservative surgical strategies for better functional outcomes. Neurosurgery 54:1375-1383; discussion 1383-1374

2. Borba LA, de Oliveira JG, Giudicissi-Filho M et al (2009) Surgical management of foramen magnum meningiomas. Neurosurg Rev 32:49-58; discussion 59-60

3. Boulton MR, Cusimano MD (2003) Foramen magnum meningiomas: concepts, classifications, and nuances. Neurosurg Focus 14:e10
4. Bret P, Guyotat J, Madarassy G et al (2000) Tentorial meningiomas. report on twenty-seven cases. Acta Neurochir (Wien) 142:513-526

5. Brown PD, Maurer MJ, Rummans TA et al (2005) A prospective study of quality of life in adults with newly diagnosed high-grade gliomas: the impact of the extent of resection on quality of life and survival. Neurosurgery 57:495-504; discussion 495-504

6. Chan RC (1984) Thompson GB (1984) Morbidity, mortality, and quality of life following surgery for intracranial meningiomas A retrospective study in 257 cases. J Neurosurg 60:52-60

7. Chi JH, Parsa AT, Berger MS et al (2006) Extended bifrontal craniotomy for midline anterior fossa meningiomas: minimization of retraction-related edema and surgical outcomes. Neurosurgery 59:ONS426-433; discussion ONS433-424

8. Dave SP, Bared A, Casiano RR (2007) Surgical outcomes and safety of transnasal endoscopic resection for anterior skull tumors. Otolaryngol Head Neck Surg 136:920-927

9. de Divitiis E, Esposito F, Cappabianca P et al (2008) Tuberculum sellae meningiomas: high route or low route? A series of 51 consecutive cases. Neurosurgery 62:556-563; discussion $556-563$

10. De Jesus O, Sekhar LN, Parikh HK et al (1996) Long-term follow-up of patients with meningiomas involving the cavernous sinus: recurrence, progression, and quality of life. Neurosurgery 39:915-919; discussion 919-920

11. Deinsberger R, Tidstrand J, Sabitzer H et al (2004) LINAC radiosurgery in skull base meningiomas. Minim Invasive Neurosurg 47:333-338

12. Drummond KJ, Zhu JJ, Black PM (2004) Meningiomas: updating basic science, management, and outcome. Neurologist 10: $113-130$

13. Dufour H, Muracciole X, Metellus P et al (2001) Long-term tumor control and functional outcome in patients with cavernous sinus meningiomas treated by radiotherapy with or without previous surgery: is there an alternative to aggressive tumor removal? Neurosurgery 48:285-294; discussion 294-286

14. Gardner PA, Kassam AB, Thomas A et al (2008) Endoscopic endonasal resection of anterior cranial base meningiomas. Neurosurgery 63:36-52; discussion 52-34

15. Gijtenbeek JM, Hop WC, Braakman R et al (1993) Surgery for intracranial meningiomas in elderly patients. Clin Neurol Neurosurg 95:291-295

16. Giovagnoli AR, Tamburini M, Boiardi A (1996) Quality of life in brain tumor patients. J Neurooncol 30:71-80

17. Hamm K, Henzel M, Gross MW et al (2008) Radiosurgery/stereotactic radiotherapy in the therapeutical concept for skull base meningiomas. Zentralbl Neurochir 69:14-21

18. Hasegawa T, Kida Y, Yoshimoto M et al (2007) Long-term outcomes of Gamma Knife surgery for cavernous sinus meningioma. J Neurosurg 107:745-751

19. Honeybul S, Neil-Dwyer G, Lang DA et al (2001) Sphenoid wing meningioma en plaque: a clinical review. Acta Neurochir (Wien) 143:749-757; discussion 758

20. Jan M, Bazeze V, Saudeau D et al (1986) Outcome of intracranial meningioma in adults. Retrospective study of a medicosurgical series of 161 meningiomas. Neurochirurgie 32:129-134

21. Jensen AW, Brown PD, Pollock BE et al (2005) Gamma knife radiosurgery of radiation-induced intracranial tumors: local control, outcomes, and complications. Int J Radiat Oncol Biol Phys 62:32-37

22. Kalkanis SN, Quinones-Hinojosa A, Buzney E et al (2000) Quality of life following surgery for intracranial meningiomas at Brigham and Women's Hospital: a study of 164 patients using a modification of the functional assessment of cancer therapy-brain questionnaire. J Neurooncol 48:233-241 
23. Kan P, Cusimano M (2006) Validation of a quality-of-life questionnaire for patients with pituitary adenoma. Can J Neurol Sci 33:80-85

24. Kim MS, Park K, Kim JH et al (2008) Gamma knife radiosurgery for orbital tumors. Clin Neurol Neurosurg 110:1003-1007

25. Kondziolka D, Flickinger JC, Perez B (1998) Judicious resection and/or radiosurgery for parasagittal meningiomas: outcomes from a multicenter review. Gamma Knife Meningioma Study Group. Neurosurgery 43:405-413; discussion 413-404

26. Kondziolka D, Mathieu D, Lunsford LD et al (2008) Radiosurgery as definitive management of intracranial meningiomas. Neurosurgery 62:53-58; discussion 58-60

27. Krupp W, Klein C, Koschny R et al (2009) Assessment of neuropsychological parameters and quality of life to evaluate outcome in patients with surgically treated supratentorial meningiomas. Neurosurgery 64:40-47; discussion 47

28. Levine ZT, Buchanan RI, Sekhar LN et al (1999) Proposed grading system to predict the extent of resection and outcomes for cranial base meningiomas. Neurosurgery 45:221-230

29. Li X, Liu M, Liu Y et al (2007) Surgical management of Tuberculum sellae meningiomas. J Clin Neurosci 14:1150-1154

30. Linskey ME, Davis SA, Ratanatharathorn V (2005) Relative roles of microsurgery and stereotactic radiosurgery for the treatment of patients with cranial meningiomas: a single surgeon 4-year integrated experience using both modalities. J Neurosurg (suppl) 102:59-70

31. Mariniello G, Maiuri F, Strianese D et al (2008) Spheno-orbital meningiomas: surgical approaches and outcome according to the intraorbital tumor extent. Zentralbl Neurochir 69:175-181

32. McDermott MW, Wilson CB (1996) Meningiomas. In: Youmans J (ed) Neurological Surgery. W.B. Saunders Company, Philadelphia, pp 2782-2825

33. Natarajan SK, Sekhar LN, Schessel D et al (2007) Petroclival meningiomas: multimodality treatment and outcomes at longterm follow-up. Neurosurgery 60:965-979; discussion 979-981
34. O’Dell MW, Barr K, Spanier D et al (1998) Functional outcome of inpatient rehabilitation in persons with brain tumors. Arch Phys Med Rehabil 79:1530-1534

35. Park CK, Jung HW, Kim JE et al (2006) The selection of the optimal therapeutic strategy for petroclival meningiomas. Surg Neurol 66:160-165; discussion 165-166

36. Raco A, Bristot R, Domenicucci M et al (1999) Meningiomas of the tuberculum sellae. Our experience in 69 cases surgically treated between 1973 and 1993. J Neurosurg Sci 43:253-260; discussion 260-252

37. Roser F, Ebner FH, Ritz R et al (2007) Management of skull based meningiomas in the elderly patient. J Clin Neurosci $14: 224-228$

38. Sachsenheimer W, Piotrowski W, Bimmler T (1992) Quality of life in patients with intracranial tumors on the basis of Karnofsky's performance status. J Neurooncol 13:177-181

39. Spektor S, Valarezo J, Fliss DM et al (2005) Olfactory groove meningiomas from neurosurgical and ear, nose, and throat perspectives: approaches, techniques, and outcomes. Neurosurgery 57:268-280; discussion 268-280

40. van Nieuwenhuizen D, Klein M, Stalpers LJ et al (2007) Differential effect of surgery and radiotherapy on neurocognitive functioning and health-related quality of life in WHO grade I meningioma patients. J Neurooncol 84:271-278

41. Weitzner MA, Meyers CA, Gelke CK et al (1995) The Functional Assessment of Cancer Therapy (FACT) scale. Development of a brain subscale and revalidation of the general version (FACT-G) in patients with primary brain tumors. Cancer 75:1151-1161

42. Zachenhofer I, Wolfsberger S, Aichholzer M et al (2006) Gamma-knife radiosurgery for cranial base meningiomas: experience of tumor control, clinical course, and morbidity in a follow-up of more than 8 years. Neurosurgery 58:28-36; discussion $28-36$ 